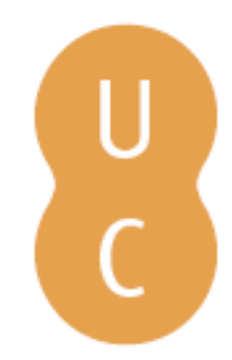

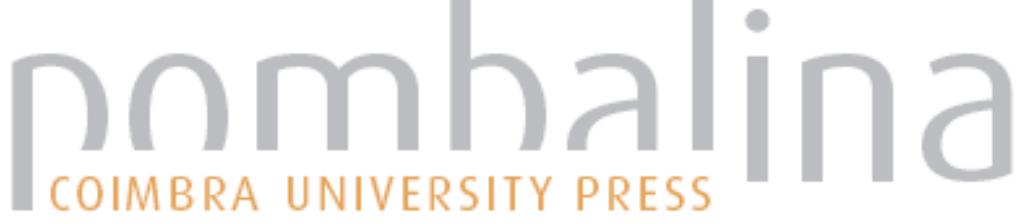

\section{Democracia desdemocratizada}

Autor(es): $\quad$ Oliveira, Flávio Ribeiro de

Publicado por: Imprensa da Universidade de Coimbra

URL

persistente: URI:http://hdl.handle.net/10316.2/45160

DOI: $\quad$ DOI:https://doi.org/10.14195/978-989-26-1679-7_10

Accessed : $\quad$ 26-Apr-2023 07:49:08

A navegação consulta e descarregamento dos títulos inseridos nas Bibliotecas Digitais UC Digitalis, UC Pombalina e UC Impactum, pressupõem a aceitação plena e sem reservas dos Termos e Condições de Uso destas Bibliotecas Digitais, disponíveis em https://digitalis.uc.pt/pt-pt/termos.

Conforme exposto nos referidos Termos e Condições de Uso, o descarregamento de títulos de acesso restrito requer uma licença válida de autorização devendo o utilizador aceder ao(s) documento(s) a partir de um endereço de IP da instituição detentora da supramencionada licença.

Ao utilizador é apenas permitido o descarregamento para uso pessoal, pelo que o emprego do(s) título(s) descarregado(s) para outro fim, designadamente comercial, carece de autorização do respetivo autor ou editor da obra.

Na medida em que todas as obras da UC Digitalis se encontram protegidas pelo Código do Direito de Autor e Direitos Conexos e demais legislação aplicável, toda a cópia, parcial ou total, deste documento, nos casos em que é legalmente admitida, deverá conter ou fazer-se acompanhar por este aviso. 

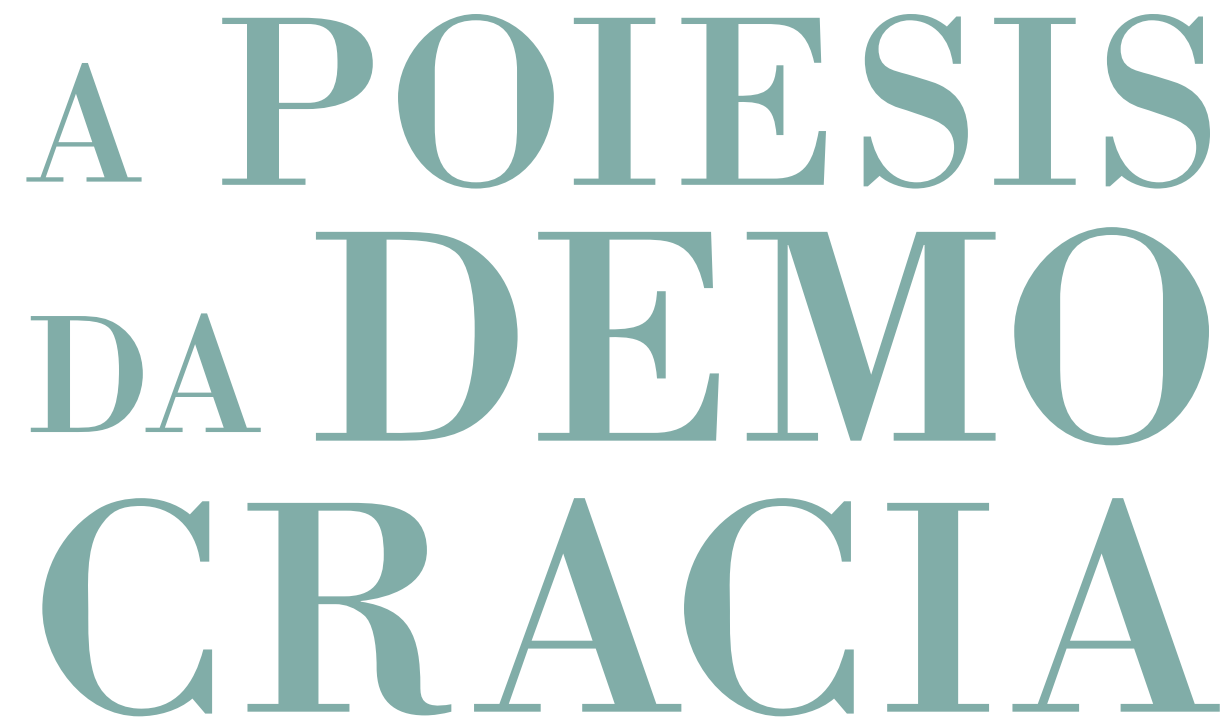

G

Breno Battistin Sebastiani, Delfim Leão,

Lugia Sano, Martinho Soares, Christian Werner

\section{CoimbraCompanions}




\section{Democracia \\ desdemocratizada}

\section{UNDEMOCRATIZED DEMOCRACY}

Flávio Ribeiro de Oliveira

UNiversidade Estadual DE CAMPINAS

ORCID | 0000-0002-4602-6981 


\section{Resumo}

Neste ensaio, procuro mostrar como a forma de democracia adotada na Modernidade - a democracia representativa - está muito mais próxima do conceito antigo de aristokratia do que daquele de demokratia.

\section{Palavras-chave}

democracia antiga, democracia moderna 


\section{Abstract}

In this essay I aim to show how the form of democracy adopted in the Modern Age - representative democracy - is closer to the ancient concept of aristokratia than it is to the ancient concept of demokratia.

\section{Keywords}

ancient democracy, modern democracy 

Podemos afirmar que a teoria antiga da democracia se resume à crítica da democracia. Não se preservou nenhuma análise teórica da democracia grega de autor que fosse contemporâneo dela e que se pudesse considerar francamente democrata ${ }^{1}$. A crítica dos antigos, contudo, é utilíssima para nós: permite-nos conceber a democracia grega em suas especificidades formais - que seus críticos consideram defeituosas - e nos apresenta a alternativa de outras formas de governo, com soluções não democráticas que permitiriam corrigir os vícios próprios da democracia. Meu propósito é demonstrar, na forma de um breve ensaio, que os teóricos da chamada democracia moderna, ao incorporar aquelas soluções não democráticas e torná-las elementos essenciais da nova forma de governo, na verdade instituem um Estado aristocrático (segundo a definição dos antigos), denominado normalmente "república" e que, mais tarde (já timidamente no fim do século XVIII, mas sobretudo a partir do século XIX), por um processo de redefinição semântica, assumiria justamente o nome daquilo que ele não é e contra o qual se opunha: democracia. Pretendo mostrar que nossa democracia burguesa nada mais é que a velha aristocracia de Platão e Aristóteles vestida de democracia e, enfim, apontar o momento preciso em que ela começa a adotar esse traje. Observe o leitor atento que nessa constatação não faço juízo de valor: talvez a democracia - a velha democracia - seja, de fato, impraticável nos Estados modernos; e se a aristocracia equivale de fato a um governo dos melhores - e não se reduz, como no Brasil contemporâneo, a uma nauseabunda kakistokratia mal disfarçada não deve ser, afinal de contas, coisa muito ruim.

1 Cf. Saxonhouse 1993: 489. Contudo, o fato de não se terem preservado textos teóricos de democratas antigos não autoriza - creio - a afirmação generalizante de Wollheim de que "ultimately, Antiquity rejected Democracy" (Wollheim 1958: 225). 


\section{Democracia Antiga}

No livro III das Histórias (80 sqq.), Heródoto reproduz um debate que teria havido entre os persas sobre qual seria a melhor forma de governo: eles buscavam aquela que se deveria introduzir na Pérsia após a morte de Cambises. Otanes defende o governo popular; Megabizo defende o governo de poucos; Dario defende a monarquia. Interessa-nos, aqui, a oposição entre a democracia e a aristocracia - portanto, deixarei de lado o discurso de Dario.

Otanes inicia sua argumentação por uma crítica da monarquia (mounarchie). A bybris caracteriza o monarca: ele faz tudo o que quer, sem precisar prestar contas daquilo que faz. Mesmo o melhor homem dentre todos - ariston andron panton - seria corrompido pela função de monarca, que necessariamente faria nascer nele a hybris: a inveja (phthonos) é inata no homem. A bybris e o phthonos levam o governante a ações dementes (atasthala). O tirano inveja os melhores (aristoi), mas dá-se bem com os piores (kakistoi) dentre os cidadãos. Ele é receptivo a calúnias. Se é admirado com moderação, ofende-se por julgar que não está sendo suficientemente cortejado; se é muito cortejado, ofende-se porque se crê adulado. Ele subverte as instituições pátrias, violenta as mulheres e mata sem julgamento.

Como alternativa à mounarchie, Otanes propõe a isonomie: trata-se do regime em que o povo comanda: plethos archon. Nessa forma de governo, não se faz nada daquilo que faz o monarca. As funções públicas (hai archai) são distribuídas por meio de sorteio (paloi: palos designa originalmente o sorteio no qual são depostas no fundo de um capacete numerosas peças contendo, cada uma, um nome; em seguida, o termo passa a designar qualquer sorteio). Esse elemento é importante como princípio geral da democracia: as archai que devem ser exercidas na prática cotidiana do governo são distribuídas entre os cidadãos por sorteio - e não por escolha, por eleição. Observo, entre parênteses, que se trata de um princípio geral, mas não absoluto: mesmo na Atenas democrática algumas das funções públicas eram ocupadas por meio de eleição, e não de sorteio. No regime popular, continua Otanes, o governo deve prestar contas da autoridade que exerce, e todas as decisões (bouleumata) são tomadas em comum (to koinon). 
Portanto, a forma de governo defendida por Otanes se funda nos seguintes princípios: todos os cidadãos governam (plethos archon), as archai são obtidas por sorteio, aqueles que as obtêm devem prestar contas de seus atos ao resto do povo e, finalmente, as decisões são tomadas em comum.

Ora, em seguida Megabizo toma a palavra e propõe que, como forma de governo, se adote a oligarquia (oligarchie). Ele concorda com toda a crítica da tirania (tyrannis, aqui assimilada à mounarchie) elaborada por Otanes. Contudo, não crê que seja um bom juízo conferir o poder (kratos) ao povo (plethos). Nada é mais insolente e violento (ouden [...] bybristoteron) e nada é mais insensato (asynetoteron) do que uma multidão que não serve para nada (bomiliou achreiou) - observemos que o ponto de vista de Megabizo é incisivo e marcará definitivamente a crítica posterior da democracia: para ele, o povo é politicamente imprestável. Megabizo continua: escapar à hybris do tirano para se entregar à do povo desenfreado (es demou akolastou bybrin) seria insuportável. O tirano, ao menos, tem conhecimento de causa; o povo, contudo, não conhece nada - na verdade, nem mesmo é capaz de conhecer (toi [...] oude ginoskein eni). De fato, como o povo poderia conhecer alguma coisa, se não recebeu instrução (out' edidachthe) e jamais viu nada de belo que lhe fosse próprio? O povo conturba as coisas, precipitando-se sobre elas sem inteligência (aneu noou). Que aqueles que querem o mal dos persas - conclui Megabizo - recorram à democracia (demos: é normal em Heródoto o emprego de demos por demokratia); quanto a nós, persas, nós devemos escolher (epilexantes - particípio aoristo do verbo epilego, "escolher", "eleger") um grupo dentre os melhores homens (andron ariston [...] bomilien) e conferir a eles o poder (kratos): é natural que os melhores homens tomem as melhores decisões.

Portanto, Megabizo propõe, como alternativa ao governo do demos - no qual as archai são distribuídas por sorteio - um governo dos aristoi, que devem ser eleitos pelo resto do povo.

A partir da leitura atenta dessa passagem, verificamos inequivocamente que Heródoto não considera democrático um governo no qual o povo elege alguns cidadãos para que eles, em nome do povo, exerçam o poder. Tal tipo de regime é um governo dos aristoi. Heródoto o denomina oligarchie; Platão e Aristóteles o chamarão de aristokratia. 
A estrutura de análise apresentada por Heródoto nessa passagem - que divide as formas de governo em três categorias, conforme o poder seja exercido por um só, por poucos ou por todos - será retomada por Platão no Político (291d sqq.): aqui, os regimes considerados serão o governo de um só (monarchia), o governo de poucos (be upo ton oligon dynasteia) e o governo da multidão (he tou plethous arche) ou democracia (demokratia), que correspondem, respectivamente, à mounarchie, à oligarchie e à isonomie de Heródoto.

Também Aristóteles, na Política (1279a sqq.), afirmará que é necessário que o poder soberano seja exercido por um só (hena), por poucos (oligous) ou pela maioria (tous pollous). Esse esquema tripartite, em Aristóteles, se multiplica por dois, pois cada uma dessas três formas de governo pode ser exercida de dois modos diferentes: ou em vista do bem comum, ou em vista do interesse dos próprios governantes. As primeiras são as boas formas de governo; estas, seus desvios - são formas decadentes. O governo de um só (monárquico) exercido em vista do bem comum é denominado basileia. O governo de poucos - os melhores - exercido em vista do bem comum é chamado de aristokratia. O governo do povo (to plethos) exercido em vista do bem comum é denominado politeia ("regime constitucional"). Em seguida, são enumeradas as degenerações dessas três boas formas de governo: quando o governo é exercido por um só homem em vista de seu próprio interesse - e não do bem comum - temos uma tyrannis. Quando o governo é exercido por poucos - pelos mais ricos ${ }^{2}$ - em vista de seu próprio interesse, temos uma oligarchia. Finalmente - e chegamos ao ponto mais baixo - quando o governo é exercido pela maioria - pelos pobres em vista de seu próprio interesse, temos uma demokratia.

Notem que, na classificação aristotélica, a democracia é a forma degradada de governo popular. A boa forma de governo popular é denominada politeia. Os defensores antigos da demokratia não adotavam essa distinção, naturalmente. Quando Péricles, no elogio de Atenas contido na oração fúnebre reproduzida por Tucídides (2, 37-41), se refere à demokratia, ele

2 Já Platão, no livro VIII da República (557a), notava que a democracia é não o governo de todos os cidadãos, mas o governo dos pobres contra os ricos. 
tem em mente justamente essa forma de governo que Aristóteles chama de politeia. Na análise que segue, considerarei em bloco essas duas formas de governo popular: uma é o reverso da outra do ponto de vista do princípio moral que orienta o governo, mas as estruturas formais de ambas são as mesmas: tanto na politeia aristotélica quanto em sua demokratia, é o povo que detém e exerce, diretamente, o poder soberano (archei).

Neste ponto, eu gostaria de chamar a atenção para uma observação de Aristóteles relativa à qualidade das democracias: para ele, ela depende da população do Estado (Política, 1318b - 1319a). A melhor espécie de democracia é aquela com uma grande população rural. Isso se deve ao fato de que os agricultores têm muito trabalho e não dispõem de tempo para frequentar as assembleias: eles trabalham, obtêm o suficiente para seu sustento e não se ocupam de política. Notem o paradoxo: para Aristóteles, a democracia mais eficiente é aquela em que a maior parte do demos renuncia ao exercício direto do poder por meio das assembleias populares. Neste ponto de vista, a melhor democracia é aquela que é privada justamente daquilo que é essencial na democracia: o exercício compartilhado do poder por todos os seus cidadãos. Estados cuja população é composta majoritariamente por artesãos, comerciantes e assalariados - observa Aristóteles - serão democracias ruins: as pessoas que compõem tais categorias costumam ficar flanando pelos espaços públicos e frequentam de bom grado as assembleias (coisa que não fazem os agricultores, que ficam dispersos pelos campos, ocupados com sua labuta cotidiana). Ou seja, o pior tipo de democracia, é aquele que possui plenamente aquilo que é essencial na democracia: participação popular. Se todo o povo resolve exercer o poder, a democracia é ruim... Essas reflexões de Aristóteles estão de acordo com a crítica platônica da democracia. Platão julga que o povo não tem qualidades intelectuais e morais - e, para ele, as duas coisas estão juntas - para governar um Estado; para ele, o governo deve ser entregue a especialistas: aos filósofos (República, 473d: ean me [...] hoi philosophoi basileuososin en tais polesin).

A essa crítica "qualitativa" da democracia - o povo não possui as qualidades necessárias para exercer o governo e seria, portanto, desastroso entregar-lhe a direção do Estado - pode-se acrescentar uma objeção que 
eu chamaria de "quantitativa" ou "técnica": a prática efetiva do governo por meio de assembleias que reúnam todo o povo foi possível nas cidades-Estado gregas; contudo, seria inviável, num Estado moderno, de grandes dimensões territoriais e populacionais, reunir em assembleia todo o povo sempre que fosse necessário tomar decisões políticas importantes. Vejam-se, a respeito da questão do número ideal de habitantes de um Estado, os comentários de Aristóteles na Política (1326a sqq.). É difícil, se não impossível - diz Aristóteles -, legislar bem em uma cidade populosa demais (ten lian polyanthropon). Esse raciocínio se aplica, com efeito incisivo, ao caso da democracia - forma de governo em que as decisões são tomadas não por um único homem ou por um pequeno grupo que poderia se reunir com facilidade, mas, idealmente, por todos os cidadãos reunidos em espaço público. Essa objeção técnica inviabiliza a prática da democracia antiga - concebida para a limitação territorial e populacional das cidades-Estado gregas - nos bem mais vastos e populosos Estados modernos. Palmer notou que, após a Revolução Francesa, era consenso o fato de que uma "democracia pura" - como a antiga - "could not exist, exept possibly in very small states with simple habits"3.

A solução aristocrata - confiar o governo a uma elite, um pequeno grupo de especialistas escolhidos por sua excelência - permite superar ambas as dificuldades. Tanto Platão como Aristóteles tinham simpatia por essa solução.

Antes de passarmos à análise das formas que o governo popular assumiu na Idade Moderna, eu gostaria de retomar e enfatizar a perspectiva dos antigos sobre um ponto que, em nossa época, é tido como um aspecto essencial e inalienável da democracia: o voto. Como já se mencionou acima, na democracia as archai eram, por princípio geral, distribuídas por sorteio. No livro VIII da República, Platão afirma que, na democracia, as archai eram, na maioria das vezes (hos to poly - a restrição se deve ao fato de que mesmo em Atenas havia exceções), distribuídas por sorteio (apo kleron) (557a). O voto - que hoje consideramos inseparável da prática democrática - era, por princípio, o meio de escolha dos ocupantes das archai nas aristocracias. Aristóteles no-lo diz claramente (Política, $1294 a$ sqq.; 1300b4

3 Palmer 1953: 204. 
sqq.): quando, do grupo de cidadãos, alguns são escolhidos para que exerçam as archai, temos um princípio aristocrático; é um elemento próprio da aristocracia a escolha, a eleição (hairesis) dos melhores - e são eles que exercem, na prática cotidiana, o governo.

\section{2. "DEMOCRACIA" MODERNA}

A experiência democrática grega tem seu auge no século V a.C. e é suprimida definitivamente com a conquista macedônia, no século IV a.C. Até o século XVIII, o termo "democracia" continuou a ser usado por historiadores e filósofos, mas apenas para se referir à democracia grega, em particular ao regime de Atenas - uma experiência histórica única circunscrita a um espaço bem delimitado e a um curto período de tempo.

A partir do século XVIII, com a Revolução Francesa e a Independência dos Estados Unidos, o termo voltaria a ser empregado com referência à atualidade, para aludir às novas formas de governo que então substituíam o Antigo Regime, na França, e o Regime Colonial, nos Estados Unidos - e não apenas como termo histórico datado, referência técnica a uma certa forma de governo extinta que outrora os atenienses adotaram.

Contudo, considerar "democrática" a nova forma de governo que se instalava suscitaria um problema do qual os primeiros teóricos da democracia moderna tinham consciência. Já vimos que a democracia antiga (direta) é impraticável nos Estados modernos, muito mais extensos territorialmente e de administração muito mais complexa. Portanto, na história do pensamento político ocidental, criou-se o conceito de uma democracia indireta, representativa, na qual alguns cidadãos notáveis são escolhidos pelo conjunto do povo para exercer efetivamente o poder em nome daqueles que os elegeram: qualquer manual de política, hoje, distingue a democracia moderna (indireta ou representativa) da antiga (direta).

Ora, já vimos que esse conceito (que hoje denominamos "democracia representativa") não era estranho aos antigos - o seu nome, contudo, era outro: o sistema de governo em que o conjunto dos cidadãos, por meio do voto, escolhe alguns, por sua virtude e competência, para que estes 
- idealmente, os melhores - exerçam o governo em nome de todos denominava-se aristokratia. A formação da democracia moderna se funda num paradoxo clamoroso: ela só foi possível na medida mesma em que deixou de ser demokratia ${ }^{4}$. A democracia moderna é um travesti da aristocracia antiga.

Neste quadro, a questão teórica que me proponho investigar é a seguinte: os antigos com certeza não viam como uma democracia o sistema político que nós, hoje, chamamos de "democracia indireta" ou "democracia representativa”. Mas e quanto aos teóricos modernos? A partir de que momento essa denominação - "democracia" - passou a ser aplicada também aos sistemas políticos populares-representativos que surgiram na segunda metade do século XVIII?

Examinemos, num primeiro momento, a situação na América. No princípio, os fundadores da nação americana não consideravam "democrático" o seu sistema de governo ("no 'democrats' fought in the American Revolution", notou Palmer5). Thomas Jefferson não gostava do termo "democrata" ${ }^{5}$. No Federalista - um dos textos basilares do sistema político americano - James Madison afirma o seguinte: "[...] democracies have ever been spectacles of turbulence and contention; have ever been found incompatible with personal security or the rights of property; and have in general been as short in their lives as they have been violent in their deaths" (The Federalist, 10)7 ${ }^{7}$. Madison está se referindo - é evidente - à democracia grega, à democracia direta: violenta, insegura e, segundo ele, já morta e enterrada. Por outro lado, Madison estabelece distinções cruciais entre aquela democracia caduca e o governo representativo que então se instalava na América: "the two great points of difference between a democracy [o sistema da antiga Atenas] and a republic [o sistema norte-americano] are: first, the delegation of the governement, in the latter, to a small number of citizens elected by the rest; secondly, the greater number of citizens, and greater sphere of country,

4 Como observou Finley (1996: 11), considerando as práticas democráticas de nossa era, "the classical theory of democracy appears to be in contradiction with the observed practice".

5 Palmer 1953: 205.

6 Palmer 1953: 207.

7 Madison, Hamilton, Jay 1952: 51 
over which the latter may be extended". (The Federalist, 10)8 ${ }^{8}$. Observe-se que, aqui, o regime norte-americano ("republic") encontra a sua fundamentação teórica numa oposição à democracia grega. Na formulação de Madison, encontramos respostas pontuais às duas principais críticas da democracia antiga - a "qualitativa" (o povo não teria competência para governar) e a "quantitativa" (a democracia não seria possível em um território extenso, de vasta população). Na "república", essas duas dificuldades estão superadas: um governo de poucos é possível mesmo em territórios vastos e populosos; neste regime - ao menos idealmente - são eleitos os melhores, com base em sua virtude e competência, para exercer o governo. A solução que Madison apresenta não é diferente daquela já proposta por Platão: trata-se da solução aristocrática, da eleição de uns poucos - os melhores - para que governem no lugar do resto da população. Já vimos que os antigos não consideravam essa forma de governo uma democracia. Vemos agora que Madison também não! Em sua argumentação, a "república” é apresentada em oposição frontal à "democracia".

Nos Estados Unidos, entre o fim do século XVIII e o início do XIX, os termos "democracy" e "democratic" não eram tão amplamente usados como são hoje - e eram empregados, normalmente, com valor pejorativo ${ }^{9}$ (por volta de 1800, qualificar alguém como "democrata" equivalia, mais ao menos, a hoje chamar alguém de "fanático" ou de "extremista"): esses termos eram normalmente associados a radicalismo político. Entre parênteses, alguém poderia se lembrar, como contra-argumento, do Democratic Republican Party, que se opunha ao Federalist Party, e que foi fundado por volta de 1791 (a data exata é incerta). Ora, na verdade ele não tinha esse nome! A denominação Democratic Republican Party é usada por cientistas políticos modernos para distingui-lo do atual Republican Party, que tem uma origem diferente. Contudo, seus fundadores, Jefferson e Madison, o denominavam simplesmente Republican Party - homônimo do partido moderno. Dentre seus contemporâneos, os únicos que se referiam ao primeiro Republican Party como "democratic" eram seus opositores, os Federalistas - e eles o

8 Madison, Hamilton, Jay 1952: 51-52

9 Cf. Palmer 1953: 207: "democracy and democrat [...] were terms of abuse and reproach". 
faziam com propósito depreciativo. Na política norte-americana, o termo só passaria a ser usado mais amplamente - e com valor positivo - décadas mais tarde, a partir da fundação do atual Democratic Party em $1828^{10}$.

Consideremos agora a situação na França. Em 1748, Montesquieu escreveu no Espírito das leis: "le suffrage par le sort est de la nature de la démocratie; le suffrage par le choix est de celle de l'aristocratie" $(2,2)^{11}$. E, com relação às condições de existência da democracia, Rousseau afirmava, no Contrato social (1762), que, “à prendre le terme dans la rigueur de l'acception, il n'a jamais existé de véritable démocratie, et il n'en existera jamais"12. Isso se deve basicamente ao fato de que uma verdadeira democracia exigiria "un État très petit où le peuple soit facile à rassembler et où chaque citoyen puisse aisément connoître tous les autres" (3, 4)13. É impossível que o povo esteja permanentemente reunido em assembleia para se ocupar dos assuntos públicos, acrescenta Rousseau. E, se o povo nomear comissões para fazer isso em seu lugar, então a forma de administração seria outra e não teríamos mais, portanto, uma democracia. Ch. Vaughan, em seu comentário do Contrato Social, nota que Rousseau, quando emprega o termo "democracia", refere-se sempre à democracia direta dos antigos. Quanto à "democracia" dos modernos, ela corresponde àquela forma de governo que Rousseau denomina "aristocratie"14.

Enfim, espero ter mostrado que, no século XVIII, estava amplamente difundida e solidamente estabelecida, tanto na França como na América, a ideia de que o sistema que substituía o Antigo Regime não era a "democracia", de que o novo governo nos Estados Unidos não era "democrático". Minha questão, a partir desta constatação, é a seguinte: quando o sistema representativo adotado pelos modernos passou a ser visto como uma democracia?

Norberto Bobbio atribui a Tocqueville o reconhecimento de que o novo Estado americano era uma forma autêntica de democracia: "si deve ad Alexis

10 Palmer 1953: 225.

11 Montesquieu 1995: 102.

12 Rousseau 1964: 226.

13 Rousseau 1964: 227.

14 Apud Rousseau 1964: 473-474. 
de Tocqueville, che nel 1835 pubblica il primo volume di De la démocratie en Amérique, il riconoscimento, quasi la consacrazione, del nuovo Stato nel nuovo mondo come forma autentica della democrazia dei moderni contrapposta alla democrazia degli antichi”. Segundo Bobbio, para Tocqueville "la distinzione fra democrazia diretta e democrazia rappresentativa non ha più alcuna rilevanza"15. De fato, para Tocqueville, na democracia "tantôt le peuple en corps fait les lois, comme à Athènes; tantôt des députés, que le vote universel a créés, le représentent et agissent en son nom sous sa surveillance presque immédiate" $(1,4)^{16}$. Ou seja, aqui, pela primeira vez (segundo Bobbio), desaparece aquela distinção que até então se fazia entre a democracia, que é direta, e a república - ou aristocracia, como a denominavam os antigos e alguns dos modernos - que é representativa e na qual os representantes do povo são eleitos por sufrágio: para Tocqueville, os dois sistemas - o ateniense e o norte-americano - são, em sua essência, democracias: aquela, direta; esta, representativa.

Contudo, com relação à introdução, no pensamento político moderno, da ideia de que o governo representativo é uma forma de democracia, eu me permitiria voltar um pouco no tempo. Interessa-me um discurso pronunciado por Robespierre na Convenção em 5 de fevereiro de 1794 (portanto, mais de quarenta anos antes da publicação de De la démocratie en Amérique -I). Bobbio não menciona esse texto em Stato, governo, società: é uma pena, pois penso que a leitura atenta de uma passagem do discurso de Robespierre pode nos levar a alterar a paternidade da ideia de que os novos governos populares representativos também eram democracias. Leiamos a passagem a que me refiro.

Robespierre se pergunta quem poderia atingir os objetivos da Revolução - e responde: "le seul gouvernement démocratique ou républicain"17. Notem um detalhe gramatical significativo: a conjunção alternativa "ou”. O autor a explica: "ces deux mots sont synonimes". Robespierre continua: "la démocratie n'est pas un état où le peuple, continuellement assemblé, règle par lui même

15 Bobbio 1985: 142-143.

16 Tocqueville 1986: 109.

17 Robespierre 1965: 213. 
toutes les affaires publiques, encore moins celui où cent mille fractions du peuple, par des mesures isolées, précipitées et contradictoires, décideraient du sort de la société entière: un tel gouvernement n'a jamais existé" - e, nesse ponto, ele concorda com Rousseau. Após explicitar aquilo que a democracia não é; Robespierre apresenta uma definição positiva: "la démocratie est un état où le peuple souverain, guidé par des lois qui sont son ouvrage, fait par lui même tout ce qu'il peut bien faire, et par des délégués tout ce qu'il ne peut faire lui même"18. Portanto, podemos constatar que, para Robespierre, não só o governo representativo é uma democracia: ele é $a$ democracia, sua forma única e autêntica. Robespierre - como Rousseau, anos antes - sustenta que a democracia direta nunca existiu de fato (perspectiva que tem sido retomada seriamente por cientistas políticos até nossos dias: como notou Euben, há os que afirmam que "Athenian democracy is also represented as a myth" e que ela é "more political projection than historical fact"19). Contudo, para Rousseau (e para os antigos) o sistema representativo não era uma democracia, e sim uma aristocracia. A novidade teórica apresentada por Robespierre é o fato de que pela primeira vez - creio $^{20}$ - essa forma de governo é definida como democrática; afirma-se pela primeira vez que um dos novos grandes Estados populares surgidos no século XVIII é uma democracia (e não uma aristocracia ou república). Essa definição de democracia é nova no pensamento político ocidental: ela inclui, no conceito de democracia, um elemento - a eleição, por meio do voto, de representantes do povo que exercerão o governo em seu nome - que nem os antigos, nem a maioria dos modernos consideravam democrático.

Com a morte de Robespierre, menos de seis meses após ter pronunciado aquele discurso, e o fim do Terror, o termo "democracia", ligado no imaginário político a Robespierre e ao radicalismo do período mais brutal da Revolução,

18 Robespierre 1965: 214.

19 Euben 1993: 478.

20 Pois esta circunstância - "pela primeira vez" - deve ser vista com prudência: os textos do período constituem uma bibliografia vastíssima e, muitas vezes, de difícil acesso. Uma afirmação peremptória exigiria um trabalho de pesquisa muito mais amplo. 
praticamente cai no esquecimento ${ }^{21}$ - até Tocqueville, que o resgata e o associa à bem-sucedida república norte-americana.

O fato é que, com o tempo, os governos populares burgueses instalados no século XVIII passaram a se considerar democracias - e se consideram até hoje. A estratégia que, durante todo o século XIX, subjaz a essa apropriação do conceito de democracia por uma forma de governo que é, em sua essência, aristocrática (pelo menos segundo as categorias adotadas pelos pensadores políticos antigos) parece-me evidente: trata-se de associar a experiência moderna à cultura grega - sobretudo àqueles seus aspectos ligados às noções de ordem, equilíbrio, justiça e razão - e, por meio do prestígio de que gozava a civilização grega, valorizar e legitimar a nova forma de governo que, na Europa e na América, nascia em oposição à velha aristocracia (fato que, neste caso, dificultaria política e retoricamente a adoção de um conceito grego mais exato - aristocracia).

\section{A aristocracia desaristocratizada}

Que o leitor me permita, para concluir, algumas reflexões livres. As formas de governo que hoje se propõem como "democráticas" adotam, para superar a dupla dificuldade que mencionei acima - inépcia do povo para o exercício do governo e impossibilidade de exercício pleno da democracia direta em Estados de vasto território - o princípio aristocrático de escolha dos melhores por meio do voto, para que eles exerçam o poder em nome do povo. Esse princípio é justamente o que caracteriza, em sua essência, os regimes aristocráticos. A democracia moderna, adotando-os, deixa de ser democracia (no sentido grego do termo). É como se a condição de existência prática da democracia, hoje, fosse sua desdemocratização. Contudo, permito-me fazer uma observação a respeito daquelas dificuldades sempre evocadas pelos que defendem a democracia representativa (que é uma aristocracia mal disfarçada) contra a democracia direta dos gregos. A democracia direta, dizem eles, só era possível nas pequenas dimensões

21 Cf. Palmer 1953: 216. 
territoriais das cidades-Estado, em que todos os cidadãos se conheciam e estavam familiarizados com os problemas da cidade. Ora, afirmo que o mesmo raciocínio pode se aplicar ao princípio aristocrático de escolha de uma elite governante por meio do voto: ele é adequado para pequenos Estados, nos quais todos os cidadãos se conhecem. Para escolher os melhores dentre meus concidadãos, preciso conhecê-los de fato. Nos Estados modernos, os cidadãos não conhecem aqueles que elegem. Conhecem suas imagens, fabricadas meticulosamente por meio de uma propaganda política elaborada por publicitários e marqueteiros que não estão minimamente comprometidos com os princípios da verdade e do bem comum. A escolha efetiva dos melhores só ocorrerá se depender de um voto consciente e fundado no conhecimento de fato dos problemas do Estado e das qualidades daqueles que elegemos. Caso contrário, deixamos de escolher os aristoi, e passamos a escolher aqueles cujo poder financeiro lhes permite pagar os melhores marqueteiros e publicitários. Admito que nesse processo há forças reguladoras - como a imprensa - mas, num mundo em rápida transformação e com a expansão avassaladora - e praticamente sem controle - das formas de comunicação vinculadas à internet, parece que perdemos a medida da verdade (já se fala, hoje, em pós-verdade) e, politicamente, votamos em sombras. E, se o voto não é consciente e fundado em conhecimento sólido, não temos a garantia de eleger os melhores: elegemos aqueles que foram capazes de construir a imagem mais sedutora e nos vemos atolados de novo numa situação análoga à do povo entregue à kolakeia dos astutos oradores antigos - para lembrar Platão. Nem me seria necessário o recurso fácil de solicitar ao leitor que examine o Congresso Nacional brasileiro em 2017 e se pergunte se aqueles são os melhores homens. Acredito que, estatisticamente, seria muito difícil um sorteio fazer uma seleção mais desastrosa. Aliás, também não faltam exemplos históricos de escolhas ruinosas nos países considerados mais civilizados: em 1933, o partido nazista alemão chegou ao poder por meio do voto, conforme as regras da democracia representativa. E em 2016 os norte-americanos elegeram Donald Trump como presidente. Portanto, na democracia representativa, aqueles que escolhemos - e que deveriam ser os aristoi - frequentemente não têm as qualidades morais e 
intelectuais necessárias para o exercício do governo (do mesmo modo que o povo, segundo os críticos antigos da democracia, não as teria).

Enfim, se não somos mais capazes de eleger os melhores, então a solução aristocrática proposta para solucionar os problemas da democracia se vê privada justamente daquilo que caracteriza a aristocracia - e, por isso mesmo, se mostra incapaz de resolver aqueles problemas.

Nossa democracia representativa é estado de indefinição política, que oscila entre uma democracia desdemocratizada e uma aristocracia desaristocratizada. Mas não se assuste o leitor: não proporei alguma tyrannis como alternativa desejável. A ideia da democracia representativa me parece carregada de contradições e de dificuldades teóricas e práticas, mas - creio - ainda é o melhor que temos.

\section{BIBLIOGRAFIA}

Aristóteles (1957), Politica. Oxford.

Bobbio, N. (1985), Stato, governo, società. Torino.

Euben, J. P. (1993), "Democracy Ancient and Modern", Political Science and Politics 26: 478-481.

Finley, M (1996), Democracy Ancient and Aodern. New Brunswick.

Heródoto (2003). Histoires - livre III - Thalie. Paris.

Madison, J; Hamilton, A.; Jay, J. (1952, prim. ed. 1788), The Federalist. Chicago.

Montesquieu (1995; prim. ed. 1748), De l'esprit des lois, I. Paris.

Palmer, R. R. (1953), "Notes on the Use of the Word 'Democracy' - 1789-1799", Political Science Quarterly 68: 203-226.

Platão (1970), Le politique. Paris.

Platão (2002), La république IV-VII. Paris.

Platão (1996), La république VIII-X. Paris.

Robespierre (1965), "Sur les principes de la morale politique qui doivent guider la Convention nationale dans l'administration intérieure de la République", in Discours et rapports à la Convention. Paris.

Rousseau, J.-J. (1964, prim. ed. 1762), Du contrat social. Paris.

Saxonhouse, A. W. (1993), "Athenian Democracy: Modern Mythmakers and Ancient Theorists". Political Science and Politics 26: 486-490.

Tocqueville, A. de (1986, prim. ed. 1835), De la démocratie en Amérique, I. Paris.

Thucydides. (2001), The Peloponnesian war - book II. Cambridge.

Wollheim, R. (1958), "Democracy", JHI 19: 225-242. 